Research Article

\title{
Validation and Analysis on Numerical Response of Super-High-Speed Railway Pantograph-Catenary Interaction Based on Experimental Test
}

\author{
Jia Yang $\mathbb{D},{ }^{1,2}$ Yang Song $\mathbb{C}^{3},{ }^{3}$ Xiaobing Lu $\mathbb{D}^{2},{ }^{2}$ Fuchuan Duan $\mathbb{D}^{1},{ }^{1}$ Zhigang Liu $\mathbb{D}^{1}$ \\ and Ke Chen (D) $^{2}$ \\ ${ }^{1}$ National Rail Transit Electrification and Automation Engineering Technique Research Centre, Southwest Jiaotong University, \\ Chengdu 610031, China \\ ${ }^{2}$ China Railway Eryuan Engineering Group CO. LTD.,, Chengdu 610031, China \\ ${ }^{3}$ Department of Structural Engineering, Norwegian University of Science and Technology, Trondheim 7491, Norway
}

Correspondence should be addressed to Yang Song; yang.song@ntnu.no

Received 15 March 2021; Revised 8 July 2021; Accepted 6 August 2021; Published 17 August 2021

Academic Editor: Stefano Marchesiello

Copyright $\odot 2021$ Jia Yang et al. This is an open access article distributed under the Creative Commons Attribution License, which permits unrestricted use, distribution, and reproduction in any medium, provided the original work is properly cited.

\begin{abstract}
The numerical tools can be used to facilitate the design of the railway pantograph-catenary system. The validation of the current numerical results is mostly performed at a speed slower than $350 \mathrm{~km} / \mathrm{h}$. This paper aims at the validation and analysis of the numerical results at a super-high-speed. The catenary model is constructed based on a nonlinear finite element approach employing the absolute nodal coordinate formulation. A multibody dynamics model is adopted to represent the pantograph. The measurement data are collected by an inspection vehicle equipped with an instrumented pantograph operating at $378 \mathrm{~km} / \mathrm{h}$ in Chengdu-Chongqing highspeed line. Comparing the numerical simulation and the field test shows that the present pantograph-catenary model can provide reliable numerical results at $378 \mathrm{~km} / \mathrm{h}$. The numerical analysis of pantograph-catenary interaction at super-high-speed shows that the trailing pantograph performance does not comply with the assessment standard at $378 \mathrm{~km} / \mathrm{h}$. The adjustment of double-pantograph interval and messenger wire tension can effectively improve the trailing pantograph performance.
\end{abstract}

\section{Introduction}

In the modern high-speed railway system, the pantographcatenary system is responsible for powering electric trains. The pantograph is usually installed on the train roof to contact the catenary's contact wire, constructed along the railroad, as shown in Figure 1. Generally, the current collection quality is directly determined by the interaction performance of the pantograph and catenary. The ever-increasing of train speed results in significant technical challenges [1]. One of them is to keep a stable contact between the pantograph and the catenary and ensure the electric railway's safe and reliable operation without traffic disruptions.

1.1. Problem Description. Due to the high cost of a field test, numerical modelling has been the most popular approach to study the interaction performance of pantograph-catenary, to guarantee numerical accuracy has been an urgent issue to both the scientific community and the practical industry. That is why Bruni et al. [2] organized a comparison among ten mainstream software devices to set up a benchmark for the validation of numerical results. Based on the world benchmark, the European standard community announced the latest standard, En 50318, in 2018 [3]. However, the maximum validation speed only reaches $320 \mathrm{~km} / \mathrm{h}$. In some countries, the super-high-speed railway has experienced a distinct advancement in the last several decades. Especially in China, the operating speed for most high-speed railway has reached $350 \mathrm{~km} / \mathrm{h}$. The design speed for some newly built railways has reached $380 \mathrm{~km} / \mathrm{h}$ or even $400 \mathrm{~km} / \mathrm{h}$. In the UK, the design speed for the HS2 project will be $360 \mathrm{~km} / \mathrm{h}$. The newly built Honam high-speed line in South Korea has a design speed of $400 \mathrm{~km} / \mathrm{h}$ [4]. However, no mature standard 


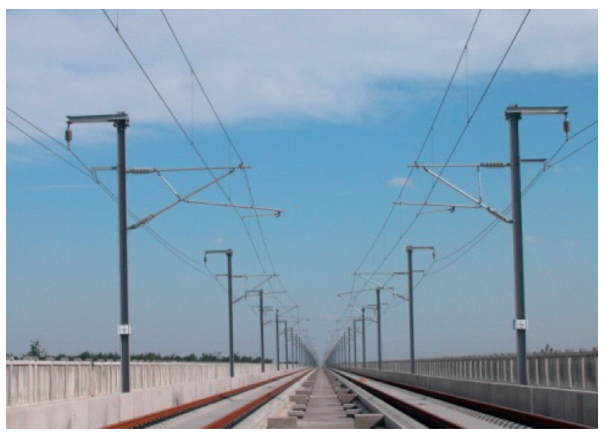

(a)

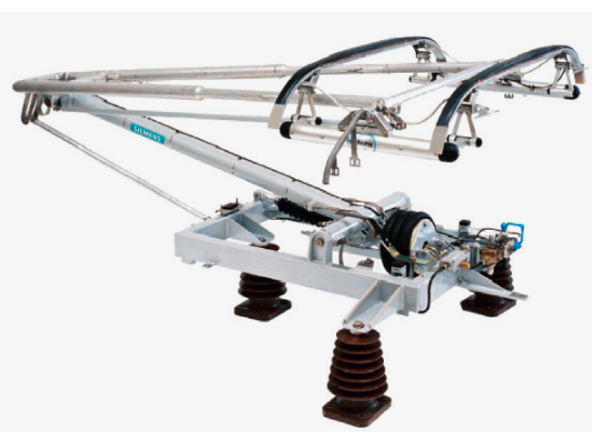

(b)

FIGURE 1: Realistic pantograph and catenary systems: (a) high-speed catenary; (b) TSG19-type pantograph.

can currently be used to validate the numerical results at more than $350 \mathrm{~km} / \mathrm{h}$. The validation at super-high-speed has been a topic of interest as it is crucial for understanding the dynamic behavior and facilitating the design and optimization of a pantograph-catenary system at super-high-speed.

1.2. Literature Review. The pantograph-catenary has been recognized as the most vulnerable part of the traction power system [5]. Therefore, the interaction performance has attracted the attention of many scholars and engineers. The numerical modelling technique of pantograph-catenary has experienced rapid development as the ever-increasing demand for the speed upgrade [6]. A lumped mass-spring system was usually used to represent the catenary in the early era [7]. Such a simple model can only describe the stiffness distribution along the span length and cannot describe the wave propagation in the contact wire [8]. With the speed upgrade, the wave propagation was proven to have an important implication on pantographcatenary dynamic performance [9]. Therefore, many continuous modelling approaches were developed based on the finite element method (FEM) [10-12], the absolute nodal coordinate formulation (ANCF) $[13,14]$, the modal superposition method [15], and the finite difference method (FDM) [16]. All of them were compared and summarized in [2] to establish a benchmark to validate numerical results. The pantograph was typically modelled by a lumped mass model with two or three degrees of freedom (DOFs) [17], which can represent two or three primary modes for a realistic one [18]. This simplification is widely accepted as it can accurately describe the response at $0-20 \mathrm{~Hz}$, which is specified to be the frequency of interest in En 50367 [19]. The advanced multibody pantograph model has been developed by some scholars $[20,21]$ to represent the physical configuration, which is of great importance to optimize the parameters [22], develop the controllers [23], and test passive dampers [24] for a better current collection quality. Apart from the simulation in ideal working conditions, the environmental perturbations and the pantograph-catenary errors are appropriately modelled to investigate their effect on the current collection quality. The wind field along the catenary was constructed $[25,26]$, and the buffeting behavior was analyzed in [27]. The traditional vortex-induced vibration in bridge engineering [28] was not the main issue for railway catenary. The aerodynamic instability has been found to have an incredible effect on the catenary [29, 30], which may cause a large amplitude vibration and make it impossible for the pantograph to operate [31]. The vehicle-track vibration was included as the vertical and spatial perturbations to assess pantographcatenary interaction performance [32-34]. The catenary model's ice-coating effect was included to evaluate the initial configuration and the contact force [35]. The catenary's equilibrium state was calculated with a defective dropper, and its effect on the contact force was evaluated $[36,37]$. The irregularities were included in the catenary to investigate their effect on the pantograph-catenary interaction $[38,39]$. The dispersion of the results can be significantly observed with the random disturbance [40]. The detection methods for the irregularities are developed based on Ensemble Empirical Mode Decomposition (EEMD) [41] and time-frequency representations [42].

To ensure numerical accuracy, some scholars devoted their attention to the field test and attempted to validate the numerical model. In [43], the simulation results were compared with several experimental tests to validate the contact force standard deviation. In [44], the catenary model was validated according to the laboratory test. However, most of these validations were performed at a speed slower than $350 \mathrm{~km} / \mathrm{h}$. The numerical accuracy at a higher speed cannot be guaranteed.

1.3. Contribution of This Paper. It is seen from the literature review that the numerical simulations of pantograph-catenary were seldom performed and validated at a super-highspeed. This shortcoming is tackled in this paper. A nonlinear finite element approach is utilized to model the catenary. The train speed is set up to $378 \mathrm{~km} / \mathrm{h}$ to reproduce the physical behavior of pantograph-catenary interaction. An instrumented pantograph with several accelerometers is installed on the train, which runs on Chengdu-Chongqing high-speed line to collect the dynamic measurement data. The results obtained from the numerical simulation and the field test are compared. An optimization approach is proposed to improve the current collection quality based on a validated numerical model. 


\section{Numerical Modelling of Pantograph- Catenary}

A mathematical model of the pantograph-catenary system is built based on the ANCF and multibody dynamics in this section. A preliminary validation is performed to validate the numerical accuracy at $320 \mathrm{~km} / \mathrm{h}$ operating speed.

2.1. Nonlinear Modelling of Catenary. The ANCF is a nonlinear finite element approach to describe the geometrical nonlinearity of large deformation. The ANCF beam element is utilized to model the tensioned wires (including contact wire, messenger wire, and stitch wire). The ANCF cable element is adopted to model the dropper wire. The steady arm is modelled by the truss element. The claws and clamps on the wire are assumed as lumped masses. The tangent stiffness matrices of the ANCF beam and cable elements have been derived in [13]. It should be noted that the axial stiffness of the cable element changes to zero when the dropper works in compression. In this way, the dropper behavior in slackness can be described.

The mass matrix $\mathbf{M}_{C}^{G}$ and the stiffness matrix $\mathbf{K}_{C}^{G}$ are assembled by the element matrix of each catenary component as follows:

$$
\begin{aligned}
\mathbf{M}_{C}^{G} & =\sum_{n_{c w}} \mathbf{M}_{c w, n}^{e}+\sum_{n_{m w}} \mathbf{M}_{m w, n}^{e}+\sum_{n_{d r}} \mathbf{M}_{d r, n}^{e}+\sum_{n_{c s}} \mathbf{M}_{s a, n}^{e}+\sum_{n_{c l}} \mathbf{M}_{c l, n}^{e}, \\
\mathbf{K}_{C}^{G} & =\sum_{n_{c w}} \mathbf{K}_{c w, n}^{e}+\sum_{n_{m w}} \mathbf{K}_{m w, n}^{e}+\sum_{n_{d r}} \mathbf{K}_{d r, n}^{e}+\sum_{n_{c s}} \mathbf{K}_{s a, n}^{e}+\sum_{n_{m s}} \mathbf{K}_{m s, n}^{e},
\end{aligned}
$$

in which $\mathbf{M}_{c w, n}^{e}, \mathbf{M}_{m w, n}^{e}, \mathbf{M}_{d r, n}^{e}, \mathbf{M}_{s a, n}^{e}$ and $\mathbf{M}_{c l, n}^{e}$ are the element mass matrix of contact wire, messenger wire, dropper, steady arm, and claws, respectively. $\mathbf{K}_{c w, n}^{e}, \mathbf{K}_{m w, n}^{e}, \mathbf{K}_{d r, n}^{e}, \mathbf{K}_{s a, n}^{e}$ and $\mathbf{K}_{m s, n}^{e}$ are the corresponding stiffness matrices. The initial configuration can be iteratively calculated through a TCUDANCF combined method reported in [13], in which the unstrained length of each element is taken as unknown to solve the equilibrium equation. Employing a Rayleigh damping matrix $\mathbf{C}_{\mathrm{C}}^{\mathrm{G}}$, the equation of motion for the catenary can be written by

$$
\mathbf{M}_{C}^{G} \ddot{\mathbf{U}}_{C}(t)+\mathbf{C}_{C}^{G} \dot{\mathbf{U}}_{C}(t)+\mathbf{K}_{C}^{G} \mathbf{U}_{C}(t)=\mathbf{F}_{C}^{G}(t),
$$

in which $\mathbf{U}_{C}(t)$ and $\mathbf{F}_{C}^{G}(t)$ are the vectors of DOF and external force. The stiffness matrix $\mathbf{K}_{C}^{G}$ is updated in each iterative step to account for the dropper slackness and geometrical nonlinearity. The Rayleigh damping coefficients identified from a realistic China high-speed railway catenary [45] are adopted in the numerical model.

2.2. Modelling of the Pantograph. A two-dimensional geometry of a pantograph is presented in Figure 2, in which F, $G$, and $P$ are the centers of mass of the lower link, lower arm, and upper arm, respectively. $m_{1}, m_{2}$, and $m_{3}$ are their respective masses; $J_{1}, J_{2}$, and $J_{3}$ are the corresponding moments of inertia; $l_{1}, l_{2}$, and $l_{3}$ are the corresponding lengths for each part; $l_{4}$ is the length of CD; $l_{5}, l_{6}$, and $l_{7}$ are the lengths of FA, GB, and $\mathrm{PC}$ respectively; $C_{\mathrm{A}}, C_{\mathrm{B}}, C_{\mathrm{C}}$ and

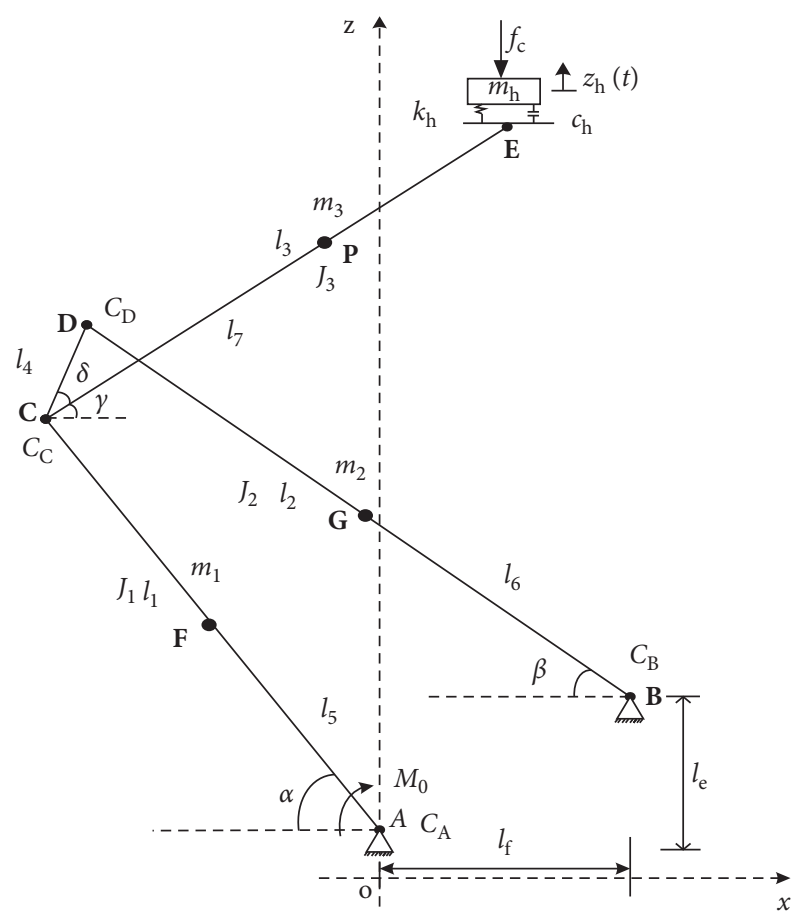

FIgURE 2: Pantograph geometry configuration.

$C_{\mathrm{D}}$ are the damping of revolute joints $\mathrm{A}, \mathrm{B}, \mathrm{C}$, and $\mathrm{D}$, respectively; $\alpha$ is the rising angle of the pantograph; $M_{0}$ is the static uplift moment; $z_{E}(t)$ and $z_{h}(t)$ are the displacement of the upper framework and the pantograph collector, respectively. $m_{\mathrm{h}}, k_{\mathrm{h}}$, and $c_{\mathrm{h}}$ are the mass, stiffness, and damping of the pantograph collector, respectively. $l_{\mathrm{e}}$ and $l_{\mathrm{f}}$ are, respectively, the vertical and horizontal distances between the two joints $\mathrm{A}$ and $\mathrm{B}$ on the base. $\delta$ is the fixed angle from the upper arm to arm CD. $f_{\mathrm{c}}$ is the contact force on the pantograph collector.

Lagrange's equations of motion for the pantograph configuration in terms of the rising angle $\alpha$ and the vertical displacement of the pantograph collector $z_{h}(t)$ can be written by

$$
\begin{gathered}
\frac{\mathrm{d}}{\mathrm{d} t}\left(\frac{\partial L}{\partial \dot{\alpha}}\right)-\frac{\partial L}{\partial \alpha}=Q_{1}, \\
\frac{\mathrm{d}}{\mathrm{d} t}\left(\frac{\partial L}{\partial \dot{z}_{h}}\right)-\frac{\partial L}{\partial z_{h}}=Q_{2},
\end{gathered}
$$

in which $L$ is the difference between the kinetic energy and the potential energy. $Q_{1}$ and $Q_{2}$ are the generalized forces acting on the two degrees-of-freedom $\alpha$ and $z_{h}(t)$, respectively, which can be derived from the principle of virtual work. The equations of motion for the multibody pantograph can be written as follows:

$$
\begin{aligned}
& h_{1}(\alpha) \ddot{\alpha}+h_{2}(\alpha) \dot{\alpha}^{2}+h_{3}(\alpha) \dot{\alpha}+h_{4}(\alpha) \\
& \quad+h_{5}\left(\alpha, \dot{\alpha}, z_{h}(t), \dot{z}_{h}(t)\right) \times \Delta(\alpha)-M_{0}=0, \\
& m_{h} \ddot{z}_{h}(t)-h_{5}\left(\alpha, \dot{\alpha}, z_{h}(t), \dot{z}_{h}(t)\right)+f_{c}(t)=0,
\end{aligned}
$$


in which the definitions of $h_{1}(\alpha), h_{2}(\alpha), h_{3}(\alpha), h_{4}(\alpha)$, $h_{5}\left(\alpha, \dot{\alpha}, z_{h}(t), \dot{z}_{h}(t)\right)$ and $\Delta(\alpha)$ are given as follows:

$$
\begin{aligned}
h_{1}(\alpha)= & m_{1} l_{5}^{2}+J_{1}+m_{2} q_{1}^{2} l_{6}^{2}+q_{1}^{2} J_{2}+m_{3} l_{1}^{2}+m_{3} q_{2}^{2} l_{7}^{2} \\
& +2 m_{3} q_{2} l_{1} l_{7} \cos (\alpha+\gamma)+q_{2}^{2} J_{3}+m_{h}\left(-l_{3} q_{2} \sin \gamma+l_{1} \sin \alpha\right)^{2}, \\
h_{2}(\alpha)= & m_{2} q_{1} l_{6}^{2} \frac{\partial q_{1}}{\partial \alpha}+q_{1} J_{2} \frac{\partial q_{1}}{\partial \alpha}+m_{3} q_{2} l_{7}^{2} \frac{\partial q_{2}}{\partial \alpha} \\
& +m_{3} l_{1} l_{7} \cos (\alpha+\gamma) \frac{\partial q_{2}}{\partial \alpha}-q_{2}\left(1+q_{2}\right) m_{3} l_{1} l_{7} \sin (\alpha+\gamma)+q_{2} J_{3} \frac{\partial q_{2}}{\partial \alpha} \\
& +m_{h}\left(-l_{3} q_{2} \sin \gamma+l_{1} \sin \alpha\right)\left(-l_{3} \frac{\partial q_{2}}{\partial \alpha} \sin (\gamma)-l_{3} q_{2}^{2} \cos (\gamma)+l_{1} \cos (\alpha)\right), \\
h_{3}(\alpha)= & C_{A}+C_{B} q_{1}^{2}+C_{C}\left(1+q_{2}\right)^{2}+C_{D}\left(q_{1}+q_{2}\right)^{2}, \\
h_{4}(\alpha)= & -k_{h}\left(z_{h}(t)-l_{1} \sin \alpha-l_{3} \sin \gamma\right)\left(l_{1} \cos \alpha+q_{2} l_{3} \cos \gamma\right) \\
& +m_{1} g l_{5} \cos \alpha+q_{1} m_{2} g l_{6} \cos \beta+m_{3} g l_{1} \cos \alpha+m_{3} q_{2} g l_{7} \cos \gamma, \\
\dot{h}_{5}\left(\alpha, \dot{\alpha}, z_{h}(t), \dot{z}_{h}(t)\right)= & -c_{h}\left(\dot{z}_{h}(t)-\left(l_{1} \cos \alpha+l_{3} q_{2} \cos \gamma\right) \dot{\alpha}\right) \\
& -k_{H}\left(z_{h}(t)-l_{1} \sin \alpha-l_{3} \sin \gamma\right), \\
\Delta(\alpha)= & \left(l_{1} \cos \alpha+q_{2} l_{3} \cos \gamma\right),
\end{aligned}
$$

where

$$
\begin{aligned}
\beta= & \arctan \frac{l_{1} \sin \alpha-l_{e}}{l_{1} \cos \alpha+l_{f}}+\arccos \frac{l_{2}^{2}+l_{t}^{2}-l_{4}^{2}}{2 l_{2} l_{t}} \\
\gamma= & \arccos \frac{l_{4}^{2}+l_{t}^{2}-l_{2}^{2}}{2 l_{4} l_{t}}-\arctan \frac{l_{1} \sin \alpha-l_{e}}{l_{1} \cos \alpha+l_{f}}-\delta, \\
q_{1}= & \frac{l_{1}^{2}+l_{f} l_{1} \cos \alpha-l_{e} l_{1} \sin \alpha}{l_{1}^{2}+l_{e}^{2}+l_{f}^{2}+2 l_{f} l_{1} \cos \alpha-2 l_{e} l_{1} \sin \alpha} \\
& +\frac{l_{t}^{2}+l_{4}^{2}-l_{2}^{2}}{l_{t} \sqrt{4 l_{t}^{2} l_{2}^{2}-\left(l_{t}^{2}+l_{2}^{2}-l_{4}^{2}\right)^{2}}} \frac{l_{1}}{l_{t}}\left(l_{f} \sin \alpha+l_{e} \cos \alpha\right)
\end{aligned}
$$

$$
\begin{aligned}
q_{2}= & -\frac{l_{1}^{2}+l_{\mathrm{f}} l_{1} \cos \alpha-l_{\mathrm{e}} l_{1} \sin \alpha}{l_{1}^{2}+l_{\mathrm{e}}^{2}+l_{\mathrm{f}}^{2}+2 l_{\mathrm{f}} l_{1} \cos \alpha-2 l_{\mathrm{e}} l_{1} \sin \alpha} \\
& +\frac{l_{\mathrm{t}}^{2}+l_{2}^{2}-l_{4}^{2}}{l_{\mathrm{t}} \sqrt{4 l_{\mathrm{t}}^{2} l_{2}^{2}-\left(l_{\mathrm{t}}^{2}+l_{4}^{2}-l_{2}^{2}\right)^{2}}} \frac{l_{1}}{l_{\mathrm{t}}}\left(l_{\mathrm{f}} \sin \alpha+l_{\mathrm{e}} \cos \alpha\right)
\end{aligned}
$$

$$
l_{t}=\sqrt{l_{1}^{2}+l_{e}^{2}+l_{f}^{2}+2 l_{f} l_{1} \cos \alpha-2 l_{e} l_{1} \sin \alpha} .
$$

2.3. Modelling of Contact. The contact between the pantograph collector and contact wire is described by the penalty function method shown in equation (15).

$$
f_{c}= \begin{cases}k_{c}\left(y_{p}-y_{c}\right), & y_{p} \geq y_{c} \\ 0, & y_{p}<y_{c} .\end{cases}
$$

In this work, a very large contact stiffness of $200000 \mathrm{~N} / \mathrm{m}$ and a high sampling frequency of $2000 \mathrm{~Hz}$ is adopted in the numerical simulation to ensure numerical stability. The element size in the contact wire is set as $0.25 \mathrm{~m}$ to ensure that numerical error cannot affect the results in the frequency range of interest. Using equation (15), the equation of motion for the pantograph-catenary system can be obtained as

$$
\mathbf{M}^{G} \ddot{U}(t)+\mathbf{C}^{G} \dot{U}(t)+\mathbf{K}^{G}(t) \mathbf{U}(t)=\mathbf{F}^{G}(t),
$$

in which $\mathbf{M}^{G}, \mathbf{C}^{G}$ and $\mathbf{K}^{G}(t)$ are the mass, damping, and stiffness matrices for the whole pantograph-catenary system, respectively. $\mathbf{F}^{G}(t)$ is the external force vector. A Newmark integration scheme is adopted to solve equation (16). The stiffness matrix $\mathbf{K}^{G}(t)$ is updated each time step to adequately describe the nonlinearity from the wire deformation and the dropper slackness.

2.4. Preliminary Verification. The work in [2] provides a benchmark for both static and dynamic validations of a 
pantograph-catenary model. Based on the reference model parameters in the benchmark, the pre-sag and elasticity of the contact wire calculated by the present model are compared with the reference values in Table 1. It shows that the pre-sag obtained by the present method is precisely the same as the benchmark. The maximum error of the elasticity is just $6.52 \%$. The dynamic validation is implemented by introducing a lumped mass pantograph model operating at $320 \mathrm{~km} / \mathrm{h}$. The contact force statistics are compared with the benchmark in Table 2. The most significant error only reaches $6.9 \%$ for the minimum contact force, which is still smaller than the threshold.

\section{Validation with Experimental Test}

To validate the numerical model presented above and analyze the pantograph-catenary interaction performance at super-higher-speed, an instrumented pantograph (see Figure 3) is mounted on an inspection vehicle (see Figure 4), which is regularly running on China high-speed network. According to En 50317 [46], the instrumented pantograph is equipped with four accelerometers on its pantograph collector, collecting the inertial part of the contact force. Two spring sensors are placed under the panhead to measure the inner forces between the panhead and the framework. The contact force can be seen as the sum of the inner forces, inertial forces, and the aerodynamic force as follows:

$$
f_{c}=\sum_{i=1}^{n_{f}} f_{\text {inner }, i}+\frac{m_{e q}}{n_{a}} \sum_{i=1}^{n_{a}} a_{\text {head }, i}+f_{\text {aero }},
$$

in which $f_{\text {inner, } i}$ is the inner force measured by sensors 10 and $11 . n_{\mathrm{f}}$ is the number of spring sensors. $m_{\mathrm{eq}}$ is the equivalent mass of the pantograph head. $n_{\mathrm{a}}$ is the number of accelerometers on the pantograph head. $a_{\text {head, } i}$ is the acceleration measured by each accelerometer. $f_{\text {aero }}$ is the aerodynamic correction part, which has been determined in a wind tunnel test.

The measurement contact force is collected from a super-high-speed test in Chengdu-Chongqing high-speed line. The design speed for this line is $350 \mathrm{~km} / \mathrm{h}$. The running speed of the inspection vehicle reaches $378 \mathrm{~km} / \mathrm{h}$ in this super-high-speed test. The two tensile sections (from $83.093 \mathrm{~km}$ to $85.981 \mathrm{~km}$ ) are taken as the analysis object. According to the design data, the catenary model with two tensile sections is constructed using the aforementioned method. The initial configuration of the catenary is presented in Figure 5. Then, the dynamic simulation is performed with a TSG-19-type pantograph. The measurement and simulation contact forces are presented in Figure 6. It is seen that the fluctuation range of the simulation contact force shows a good agreement with the measurement contact force. According to En 50317 [46], the measurement data has an up to $10 \%$ inevitable error due to the limitation of the measurement equipment. Therefore, the contact force waveform cannot be directly used for comparison. Some statistics of the contact force and uplift specified in En 50318 [3] are typically used to validate the numerical model. The comparison of these statistics is presented in Table 3. It is seen that the most important indicator, contact force standard deviation evaluated by the present model, only has a $4.17 \%$ error against the measurement data, which is much smaller than the threshold of $20 \%$. The uplifts of the panhead and the support are almost identical to the measurement values. Even though the actual maximum and minimum contact forces are not included in the validation in En 50318, the most significant difference of these values against the measurement data is still smaller than $20 \%$. Through the comparison, it can be demonstrated that the present model has good performance to evaluate the comprehensive and local behaviors of the pantograph-catenary interaction.

\section{Assessment with Numerical Results}

The current assessment standard En 50367 [19] stipulates that the statistics of the contact force and uplift should satisfy the criteria. When the train speed is over $200 \mathrm{~km} /$ $\mathrm{h}$, the mean contact force should be over $0.00047 v^{2}+60 \mathrm{~N}$, but smaller than $0.00097 v^{2}+70 \mathrm{~N}$. The statistical minimum contact force should be positive, while the actual minimum should be over $0 \mathrm{~N}$ for Chine high-speed network. The statistical and actual maximum contact force should be smaller than $350 \mathrm{~N}$ at up to $350 \mathrm{~km} / \mathrm{h}$. There is no current safety threshold for the maximum contact force at super-high-speed. It is expected that this threshold value can be increased with the increase of the mean contact force. In this section, the assessments are performed according to the standard [19] based on the numerical results. Both single-pantograph and double-pantograph operations in practice are considered.

4.1. Assessment with Single Pantograph. In the daily operation of China high-speed network, most electric motor units (EMUs) are equipped with one pantograph. When a single pantograph is used, the assessment indicators are presented in Table 4. It can be seen that all the indicators satisfy the criteria of the standard. The pantograph-catenary system shows an acceptable performance when running at $378 \mathrm{~km} /$ h.

4.2. Assessment with Double Pantographs. However, some EMUs are equipped with double pantographs to improve the carrying capacity. When double pantographs are used, the trailing pantograph performance is often deteriorated by wave propagation in the catenary [47]. A standard distance of $210 \mathrm{~m}$ between the two pantographs is used in the simulation. The contact forces of leading and trailing pantographs are presented in Figure 7. It is seen that the leading pantograph has a significantly better performance than the trailing one. The fluctuation of the trailing pantograph contact force is much more violent than the leading one. Even some contact loss can be observed. Table 5 collects the assessment indicators for both leading and trailing pantographs. It can be seen that the behavior of the leading 
TABLE 1: Static validation of the present model against the benchmark.

\begin{tabular}{|c|c|c|c|c|c|c|}
\hline \multirow{2}{*}{ Dropper No. } & \multicolumn{3}{|c|}{ Pre-sag } & \multicolumn{3}{|c|}{ Elasticity } \\
\hline & Benchmark (mm) & Present $(\mathrm{mm})$ & Error (\%) & Benchmark $(\mathrm{mm} / \mathrm{N})$ & Present $(\mathrm{mm} / \mathrm{N})$ & Error (\%) \\
\hline Sup & 0 & 0 & 0 & 0.206 & 0.19257 & 6.52 \\
\hline 1 & 0 & 0 & 0 & 0.165 & 0.15647 & 5.17 \\
\hline 2 & 24 & 24 & 0 & 0.273 & 0.26774 & 1.93 \\
\hline 3 & 41 & 41 & 0 & 0.345 & 0.3268 & 5.28 \\
\hline 4 & 52 & 52 & 0 & 0.388 & 0.36832 & 5.07 \\
\hline 5 & 55 & 55 & 0 & 0.4 & 0.37509 & 6.23 \\
\hline 6 & 52 & 52 & 0 & 0.388 & 0.36832 & 5.07 \\
\hline 7 & 41 & 41 & 0 & 0.345 & 0.3268 & 5.28 \\
\hline 8 & 24 & 24 & 0 & 0.273 & 0.26774 & 1.93 \\
\hline 9 & 0 & 0 & 0 & 0.165 & 0.15647 & 5.17 \\
\hline Sup & 0 & 0 & 0 & 0.206 & 0.19257 & 6.52 \\
\hline
\end{tabular}

TABle 2: Dynamic validation of the present model against the benchmark.

\begin{tabular}{lccc}
\hline & Benchmark & Present model & Error (\%) \\
\hline$F_{m}(\mathrm{~N})$ & 169 & 169.15 & 0.09 \\
$\sigma(0-20 \mathrm{~Hz})(\mathrm{N})$ & 53.91 & 52.59 & 2.45 \\
$\sigma(0-2 \mathrm{~Hz})(\mathrm{N})$ & 38.27 & 38.25 & 0.05 \\
$\sigma(0-5 \mathrm{~Hz})(\mathrm{N})$ & 41.04 & 41.00 & 0.10 \\
$\sigma(5-20 \mathrm{~Hz})(\mathrm{N})$ & 34.80 & 32.99 & 5.20 \\
$F_{\max }(\mathrm{N})$ & 313.22 & 305.85 & 2.35 \\
$F_{\min }(\mathrm{N})$ & 60.40 & 56.22 & 6.9 \\
\hline
\end{tabular}

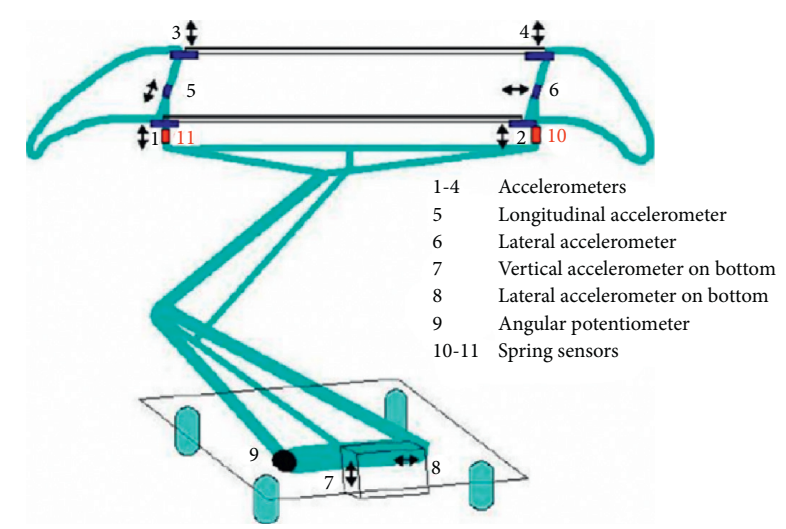

FIGURE 3: Instrumented pantograph to measure contact force.

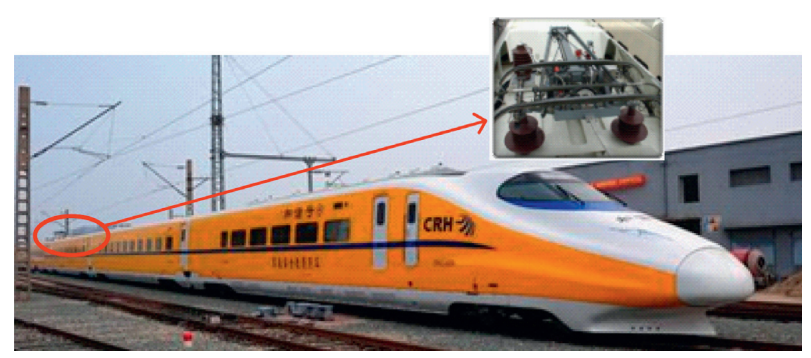

FIGURE 4: High-speed inspection vehicle.

pantograph is very similar to a single pantograph. However, almost all the indicators of the trailing pantograph do not satisfy the criteria. When the train is operating at $378 \mathrm{~km} / \mathrm{h}$, the trailing pantograph performance cannot pass the acceptance. In Section 4.3, some suggestions are proposed to improve the trailing pantograph performance at a superhigh-speed.

4.3. Suggestions for Improving Trailing Pantograph Performance at Super-High-Speed. The most effective measure to improve the trailing pantograph performance is to increase the tension in the contact wire. The current tension in the contact wire has reached $30 \mathrm{kN}$. Due to the material limitation, the extra tension will increase the risk of the contact wire breakage. Therefore, this section investigates the potential measure to improve the trailing pantograph performance at a given tension class. According to the authors' previous research [48], the trailing pantograph performance depends on the match between the catenary mode excited by the pantograph and the double pantograph's interval. If the pantographs' interval is consistent with the structural wavelength (which can be extracted from the mode), a resonance will happen, and the trailing pantograph's bad performance is expected. Based on this theory, the pantograph interval or messenger wire tension may be adjusted to avoid the resonance and achieve good performance for the trailing pantograph.

4.3.1. Adjustment of Pantograph Interval. The nominal pantograph interval is $210 \mathrm{~m}$. According to China railway standard, the minimum and maximum pantograph intervals are $200 \mathrm{~m}$ and $215 \mathrm{~m}$, respectively. In this analysis, the pantograph interval is defined (from $190 \mathrm{~m}$ to $230 \mathrm{~m}$ ) slightly over the standard range to investigate the potential performance. The dynamic simulations of double pantographs-catenary interaction are performed with different messenger wire tensions. The contact force statistics of the leading pantograph are presented in Figure 8. It is seen that the change of the pantograph interval does not have a distinct effect on the leading pantograph performance. The contact force statistics of the trailing pantograph are presented in Figure 9. Unlike the leading pantograph, the trailing pantograph behavior is significantly changed by slightly adjusting the pantograph interval. When the interval is from $190 \mathrm{~m}$ to $205 \mathrm{~m}$, a positive statistical minimum contact force can be 


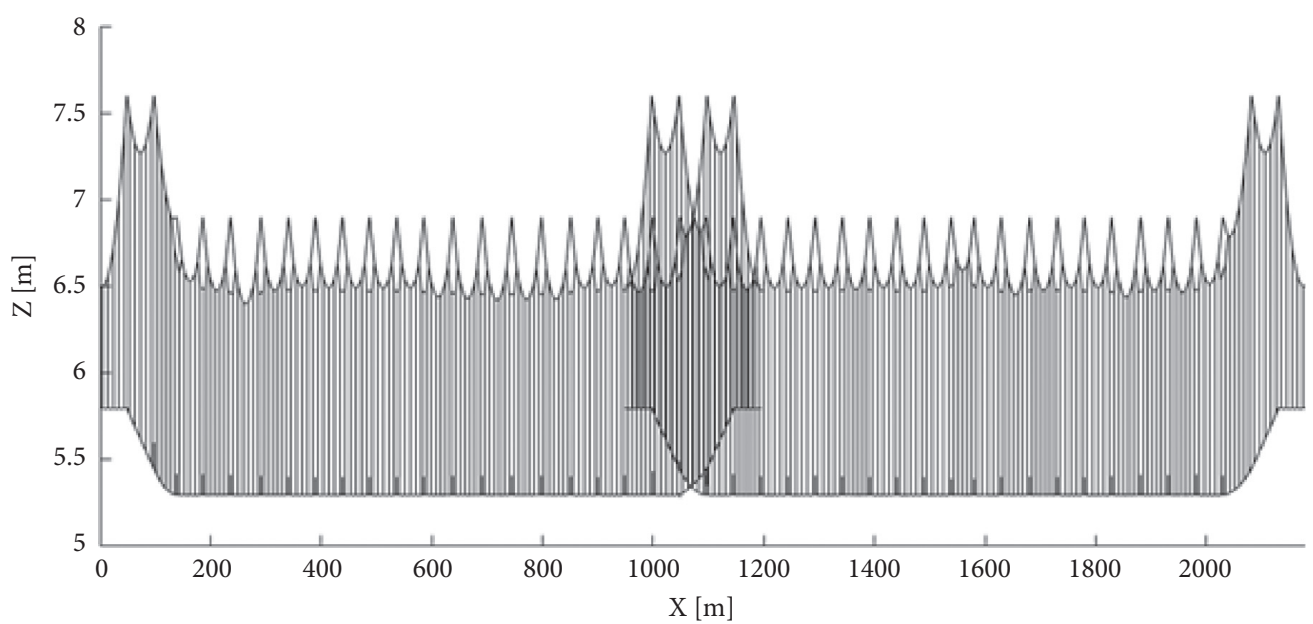

(a)

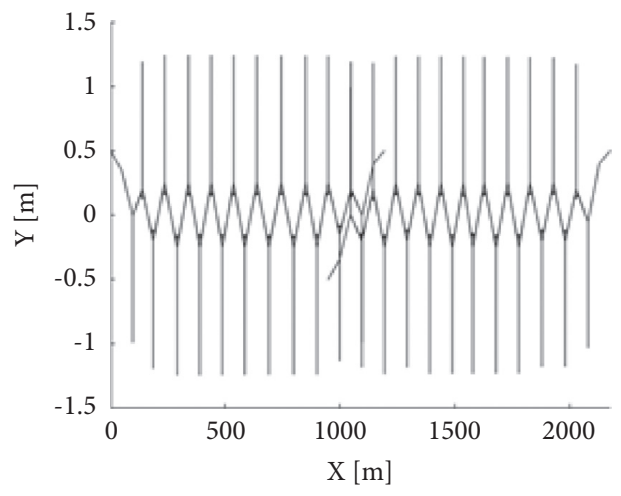

(b)

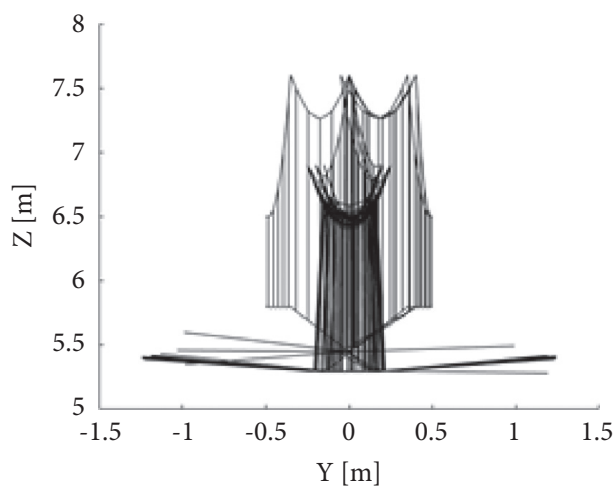

(c)

FIGURE 5: Catenary initial configuration using the design data of Chengdu-Chongqing high-speed line: (a) front view; (b) side view; (c) top view.

obtained. Especially, when the interval is $205 \mathrm{~m}$, both the statistical and actual minimum contact forces are positive. It should be noted that that the maximum contact forces of the trailing pantograph are always more extensive than the threshold $350 \mathrm{~N}$. But this threshold is defined for the operating speed lower than $350 \mathrm{~km} / \mathrm{h}$ and should be increased at super-high-speed as the increase of the mean contact force. Therefore, the numerical result indicates an acceptable performance of the trailing pantograph at the pantograph interval of $205 \mathrm{~m}$.
4.3.2. Adjustment of Messenger Wire Tension. The nominal messenger wire tension for the analysis catenary is $21 \mathrm{kN}$. In the numerical simulations, the messenger wire tension is changed from $19 \mathrm{kN}$ to $29 \mathrm{kN}$, which does not exceed the contact wire tension. The contact force statistics of the leading pantograph with different messenger wire tensions are presented in Figure 10. It is seen that the change of the messenger wire tension has some effect on the leading pantograph performance. Nevertheless, all the statistics are still within the acceptance range. When the messenger wire 


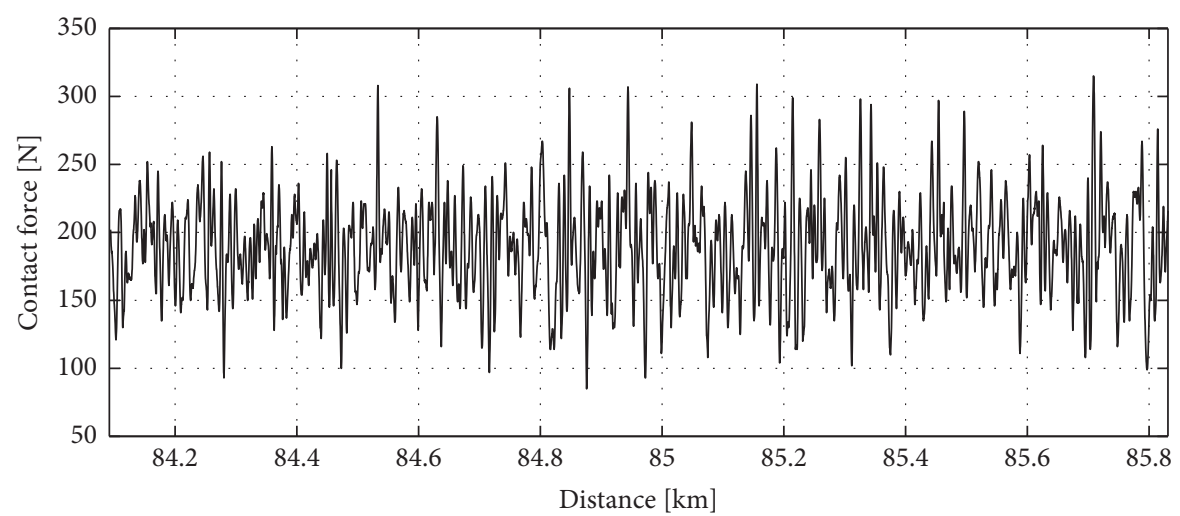

(a)

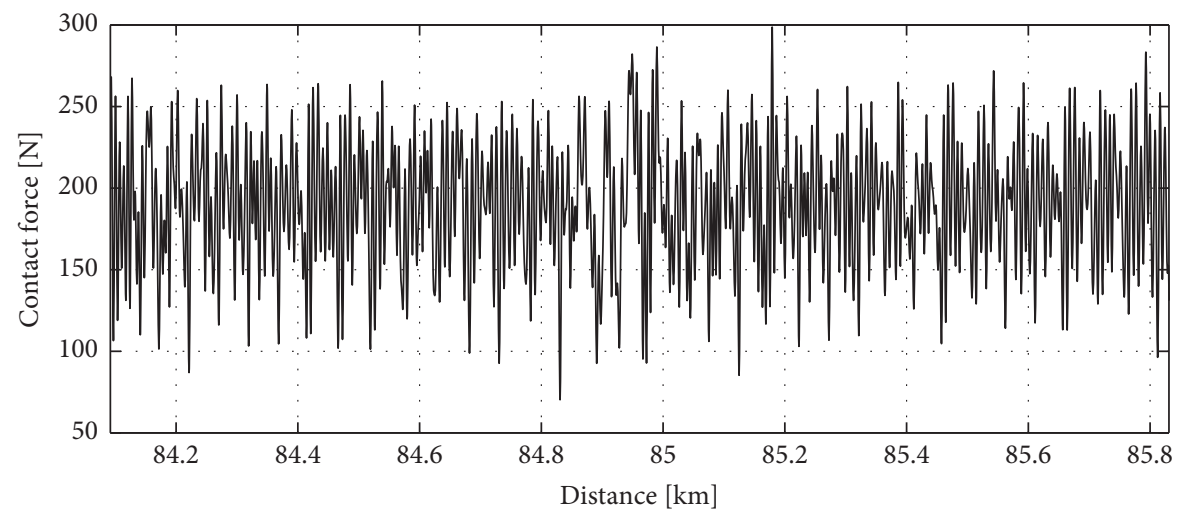

(b)

Figure 6: Contact force time history: (a) measurement; (b) simulation.

TABLE 3: Comparison of critical indicators between simulation and measurement.

\begin{tabular}{lcccc}
\hline & Measurement & Simulation & Error & Threshold \\
\hline Speed $(\mathrm{km} / \mathrm{h})$ & 378 & 378 & - & - \\
Mean $(\mathrm{N})$ & $189.24 \mathrm{~N}$ & $189.96 \mathrm{~N}$ & $0.72 \mathrm{~N}$ & $\pm 2.5 \mathrm{~N}$ \\
Standard deviation (N) & $35.26 \mathrm{~N}$ & $36.73 \mathrm{~N}$ & $4.17 \%$ & $\pm 20 \%$ \\
Statistical maximum (N) & $288.8 \mathrm{~N}$ & $300.15 \mathrm{~N}$ & $3.9 \%$ & - \\
Statistical minimum (N) & $87.5 \mathrm{~N}$ & $79.77 \mathrm{~N}$ & $8.83 \%$ & - \\
Range of panhead vibration & $68 \mathrm{~mm}$ & $68.3 \mathrm{~mm}$ & $0.3 \mathrm{~mm}$ & $-10 \mathrm{~mm} ;+20 \mathrm{~mm}$ \\
Support uplift & $90 \mathrm{~mm}$ & $90.82 \mathrm{~mm}$ & $0.82 \mathrm{~mm}$ & - \\
Actual maximum & $315.00 \mathrm{~N}$ & $298.68 \mathrm{~N}$ & $5.18 \%$ & - \\
Actual minimum & $85.00 \mathrm{~N}$ & $70.30 \mathrm{~N}$ & $29 \%$ & - \\
\hline
\end{tabular}

TABle 4: Assessment of simulation results against En 50367 (single pantograph).

\begin{tabular}{lcc}
\hline & Simulation result & Acceptance \\
\hline Mean (N) & $189.96 \mathrm{~N}$ & $>127.16 \mathrm{~N}$ and $<208.60$ \\
Statistical maximum (N) & $300.15 \mathrm{~N}$ & $<350 \mathrm{~N}$ (up to $350 \mathrm{~km} / \mathrm{h}$ ) \\
Statistical minimum (N) & $79.77 \mathrm{~N}$ & $>0 \mathrm{~N}$ \\
Support uplift & $90.82 \mathrm{~mm}$ & $<150 \mathrm{~mm}$ \\
Actual maximum & $298.68 \mathrm{~N}$ & $<350 \mathrm{~N}$ (up to $350 \mathrm{~km} / \mathrm{h}$ ) \\
Actual minimum & $70.30 \mathrm{~N}$ & $>10 \mathrm{~N}$ \\
\hline
\end{tabular}

tension is $29 \mathrm{kN}$, the leading pantograph has the best performance. The contact force statistics of the trailing pantograph are presented in Figure 11. It is seen that, for the messenger wire tensions from $19 \mathrm{kN}$ to $25 \mathrm{kN}$, the minimum contact forces are smaller than $0 \mathrm{~N}$. Only when the messenger wire tensions are $27 \mathrm{kN}$ and $29 \mathrm{kN}$, both the statistical 


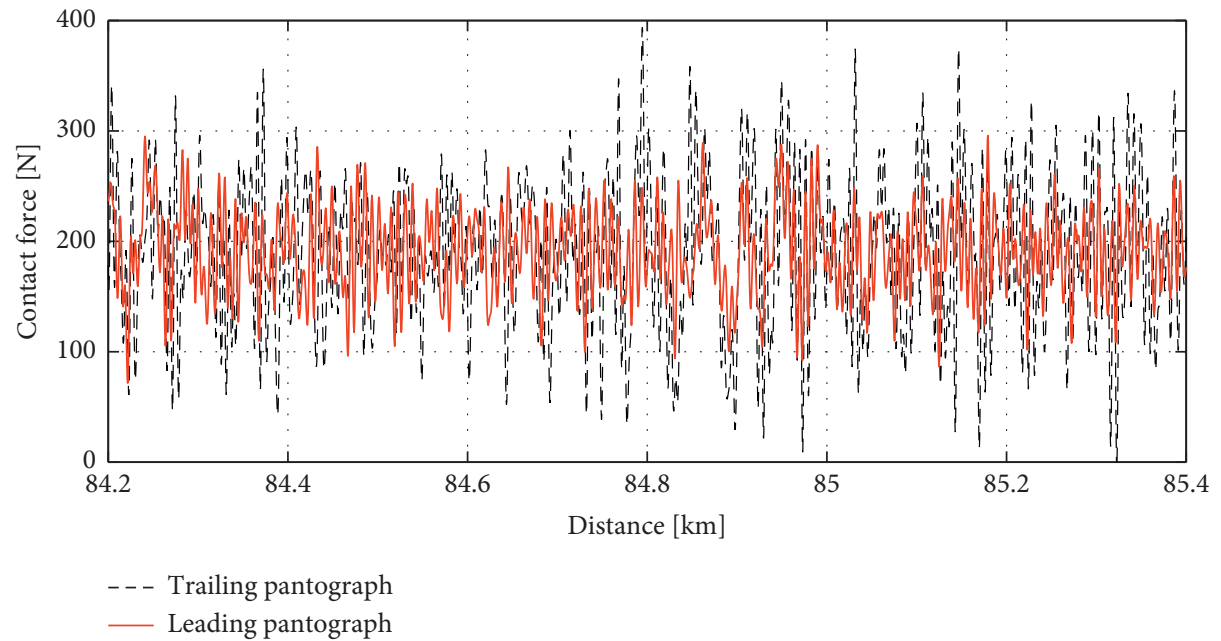

Figure 7: Simulation contact force with double pantographs.

TABLE 5: Assessment of simulation results against En 50367 (double pantograph).

\begin{tabular}{lccc}
\hline & Leading pantograph & Trailing pantograph & Acceptance \\
\hline Mean (N) & $189.45 \mathrm{~N}$ & 189.58 & $>127.16 \mathrm{~N}$ and $<208.60$ \\
Statistical maximum (N) & $300.43 \mathrm{~N}$ & $\mathbf{3 8 5 . 9 0 ~ N}$ & $<350 \mathrm{~N}($ up to $350 \mathrm{~km} / \mathrm{h}$ ) \\
Statistical minimum (N) & $78.47 \mathrm{~N}$ & $-\mathbf{6 . 7 4 ~ N}$ & $>0 \mathrm{~N}$ \\
Support uplift & $92.4 \mathrm{~mm}$ & $101.2 \mathrm{~mm}$ & $<150 \mathrm{~mm}$ \\
Actual maximum & $295.81 \mathrm{~N}$ & $\mathbf{3 9 3 . 8 2} \mathbf{N}$ & $\mathbf{0 N}$ \\
Actual minimum & $86.51 \mathrm{~N}$ & $\mathbf{0}$ & $>0 \mathrm{~N}$ \\
\hline
\end{tabular}

Unsatisfactory results are in bold.

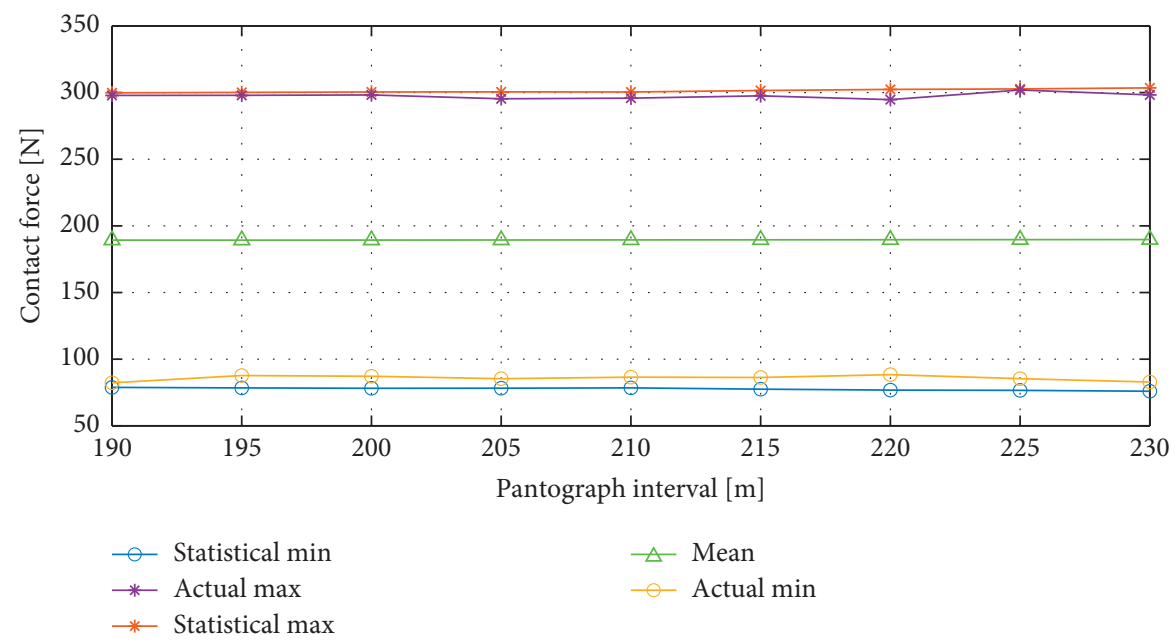

FIGURE 8: Contact force statistics of the leading pantograph with different pantograph intervals.

and actual minimum contact forces are positive. The actual and statistical maximum contact forces are also relatively lower than in other cases.

\subsubsection{Adjustment of Both Pantograph Interval and Messenger} Wire Tension. The actual and statistical minimum contact force of the trailing pantograph versus messenger wire tension and pantograph interval are presented in Figures 12 and 13 , respectively. It is seen that when the messenger wire tension increases to $27 \mathrm{kN}$ and $29 \mathrm{kN}$, the trailing pantograph generally has a more acceptable performance. With a messenger wire tension of $27 \mathrm{kN}$, both actual and statistical minimum contact forces are positive at a pantograph interval from 190 to $215 \mathrm{~m}$. With a messenger wire tension of $29 \mathrm{kN}$, both actual and statistical minimum contact forces are positive for most pantograph intervals except $205 \mathrm{~m}, 220 \mathrm{~m}$, and $230 \mathrm{~m}$. For other messenger wire tensions, only two acceptable cases can be observed. 


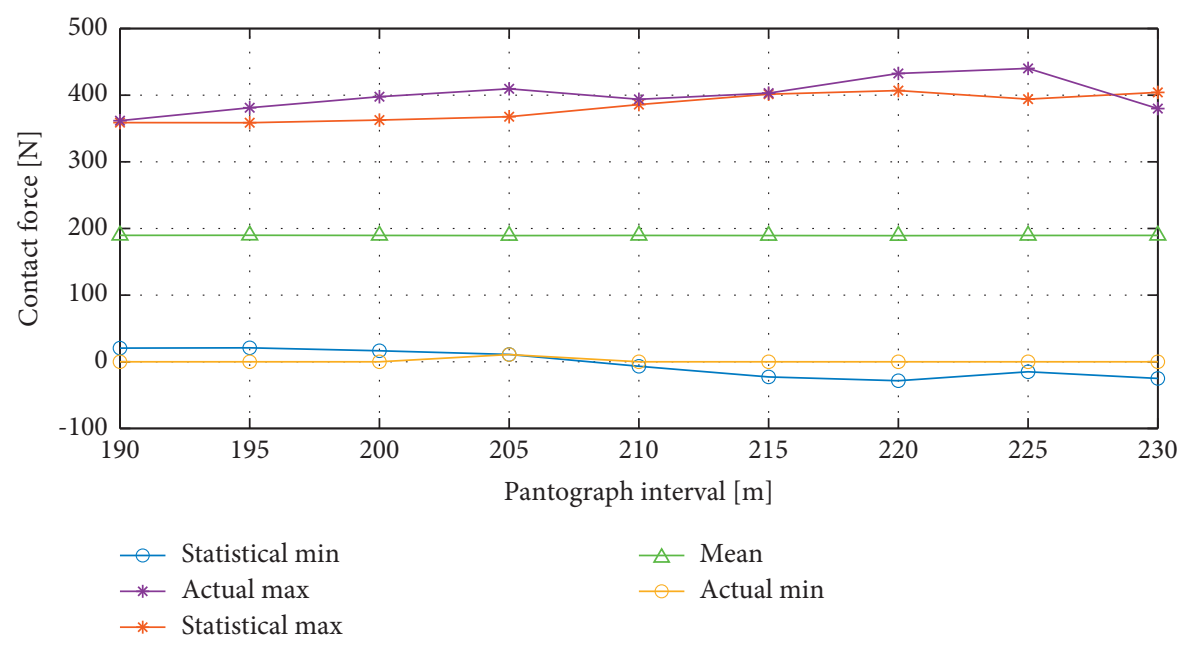

FIgURE 9: Contact force statistics of the trailing pantograph with different pantograph intervals.

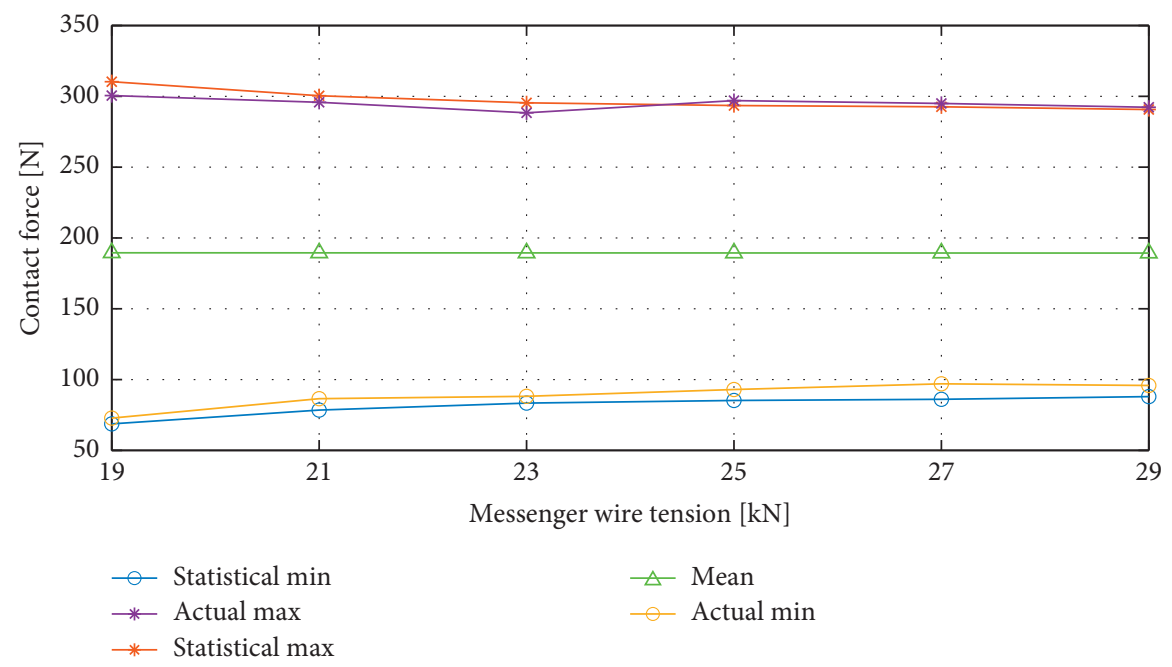

FIgURE 10: Contact force statistics of the leading pantograph versus messenger wire tension.

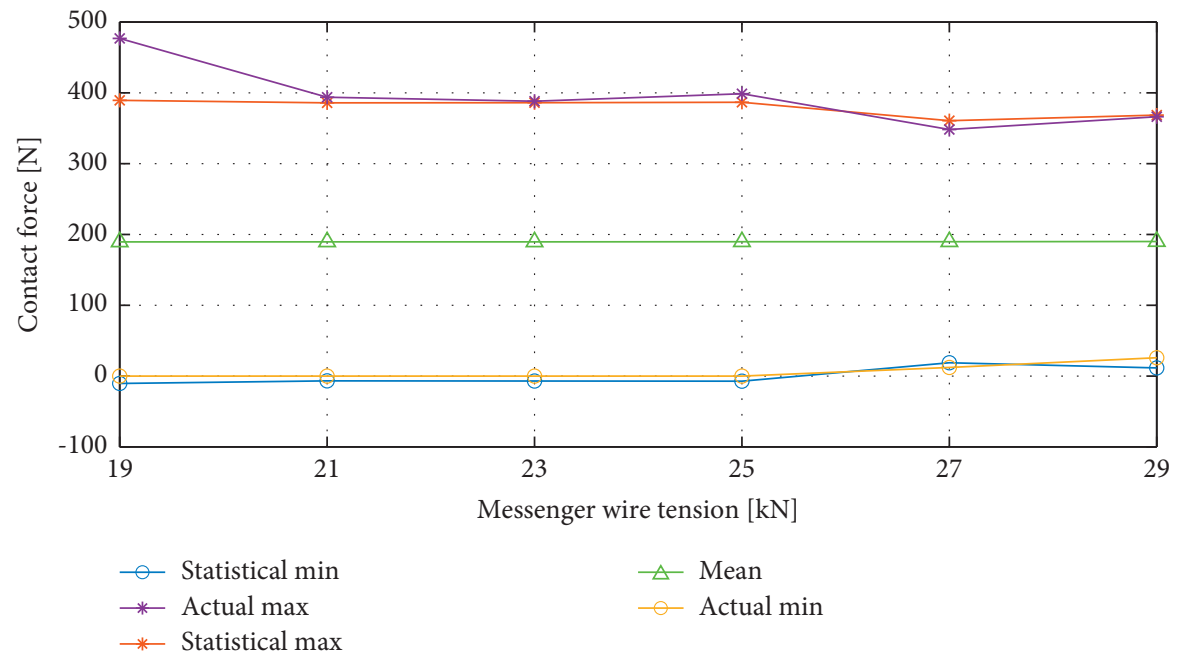

FIgURE 11: Contact force statistics of the trailing pantograph versus messenger wire tension. 


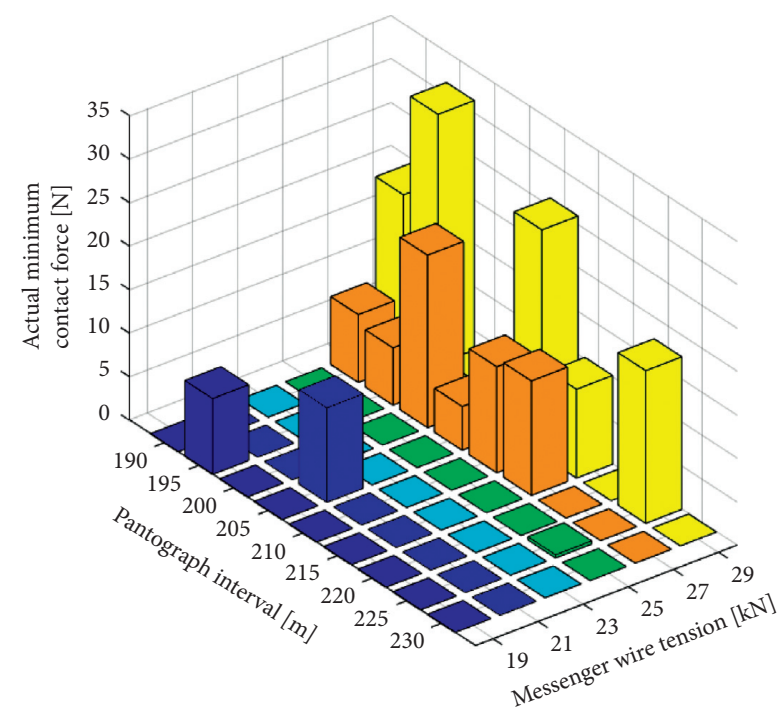

Figure 12: Actual minimum contact force of the trailing pantograph versus messenger wire tension and pantograph interval.

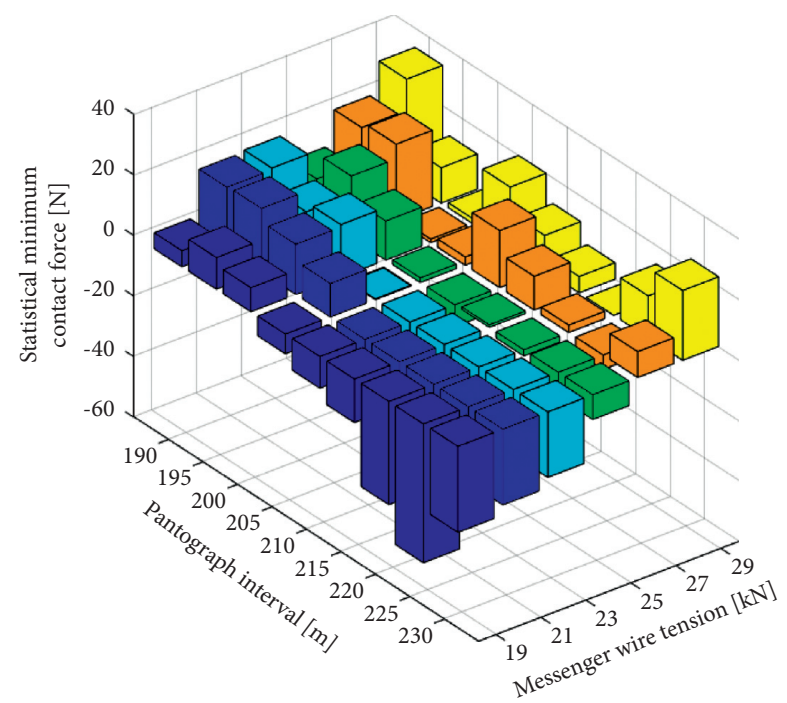

FIgURE 13: Statistical minimum contact force of the trailing pantograph versus messenger wire tension and pantograph interval.

\section{Conclusions}

Most current numerical simulations of pantograph-catenary are mostly performed and validated at a speed of no more than $350 \mathrm{~km} / \mathrm{h}$. In this paper, an instrumented pantograph is mounted on a high-speed inspection vehicle operating at $378 \mathrm{~km} / \mathrm{h}$ in China high-speed network. A numerical model of pantograph-catenary is constructed based on ANCF and multibody dynamics. Comparing the contact force and dynamic uplift between the numerical simulation and the field test is performed. Some conclusions can be drawn as follows:

(1) The proposed pantograph-catenary model can provide reliable numerical results at $378 \mathrm{~km} / \mathrm{h}$. The statistics of contact force and uplift have a high similarity with the measurement data.

(2) When a single pantograph is used, the pantographcatenary interaction performance still satisfies the assessment standard at $378 \mathrm{~km} / \mathrm{h}$. However, when the double pantographs are used, the trailing pantograph performance is no longer acceptable.

(3) The adjustment of double-pantograph interval and messenger wire tension can effectively improve the trailing pantograph performance. These measures are promising in practice as they do not need to increase the catenary tension class.

It should be noted that the assessment in this paper uses the contact force with a $20 \mathrm{~Hz}$ cut-off frequency. This frequency range may not be enough to describe the interaction behaviors of the pantograph-catenary and deserves to be improved. But it will entail some necessary fundamental research in the future, including the development of measurement equipment for high-frequency data, the numerical scheme for simulating high-frequency behaviors, and the appropriate modelling of the disturbances, which may affect high-frequency performance. The analysis of this paper also indicates that the pantograph interval or catenary parameters may be adjusted to achieve good performance for the trailing pantograph. But it is not easy to give an analytical explanation on the selection of pantographs' interval or catenary parameters. Firstly, the catenary has infinite modes mathematically. One or several dominant modes are excited by moving pantographs with a given speed. An appropriate solution is desired to explicitly determine which mode is the dominant one at a given speed. Secondly, the catenary mode is time-varying due to the strong nonlinearity, including the geometrical nonlinearity and dropper slackness. Reasonable solutions are expected to quantify the effect of the timevarying mode on the interaction performance.

\section{Data Availability}

No data were used in this paper.

\section{Conflicts of Interest}

The authors declare no conflicts of interest.

\section{Authors' Contributions}

Conceptualization was performed by J. Yang and Y. Song; methodology was developed by J. Yang; software was provided by Y. Song; validation was performed by J. Yang, Y. Song, and X. Lu; formal analysis was done by F. Duan; investigation was done by Y. Song; resources were provided by J. Yang, Y. Song, and Z. Liu; data curation was performed by J. Yang, F. Duan, and X. Lu; original draft was written by Y. Song; reviewing and editing were performed by J. Yang, F. Duan, Z. Liu, and X. Lu; supervision was done by Z. Liu; project administration was done by $Z$. Liu; funding acquisition was done by $Z$. Liu. All the authors have read and agreed to the published version of the manuscript. 


\section{Acknowledgments}

The authors express their gratitude to the China Academy of Railway Sciences for the assistance to acquire the measurement data. This research was funded by the National Natural Science Foundation of China (U1734202) and the Funding of Chengdu Guojia Electrical Engineering Co. Ltd (No. NEEC-2019-B09 and NEEC-2018-A02). The APC was funded by the National Natural Science Foundation of China.

\section{References}

[1] S. Iwnicki, Handbook of Railway Vehicle Dynamics, CRC Press, Boca Raton, FL, USA, 2006.

[2] S. Bruni, J. Ambrosio, A. Carnicero et al., "The results of the pantograph-catenary interaction benchmark," Vehicle System Dynamics, vol. 53, no. 3, pp. 412-435, 2015.

[3] BS EN 50318:2018, "Railway applications-Current collection systems: Validation of simulation of the dynamic interaction between pantograph and overhead contact line," European Standards (EN): Brussels, vol. 3, 2018.

[4] J. H. Lee, T. W. Park, H. K. Oh, and Y. G. Kim, “Analysis of dynamic interaction between catenary and pantograph with experimental verification and performance evaluation in new high-speed line," Vehicle System Dynamics, vol. 53, no. 8, pp. 1117-1134, 2015.

[5] H. Chen and B. Jiang, "A review of fault detection and diagnosis for the traction system in high-speed trains," IEEE Transactions on Intelligent Transportation Systems, vol. 21, no. 2, pp. 450-465, 2020.

[6] J. Ambrósio, J. Pombo, M. Pereira, P. Antunes, and A. Mósca, "Recent developments in pantograph-catenary interaction modelling and analysis," International Journal of Reality Therapy, vol. 1, no. 1, pp. 249-278, 2012.

[7] T. X. Wu and M. J. Brennan, "Dynamic stiffness of a railway overhead wire system and its effect on pantograph-catenary system dynamics," Journal of Sound and Vibration, vol. 219, no. 3, pp. 483-502, 1999.

[8] G. Poetsch, J. Evans, R. Meisinger et al., "Pantograph/catenary dynamics and control," Vehicle System Dynamics, vol. 28, no. 2-3, pp. 159-195, 1997.

[9] Y. Song, Z. Liu, F. Duan, Z. Xu, and X. Lu, "Wave propagation analysis in high-speed railway catenary system subjected to a moving pantograph," Applied Mathematical Modelling, vol. 59, pp. $20-38,2018$.

[10] Y. Song, P. Antunes, J. Pombo, and Z. Liu, “A methodology to study high-speed pantograph-catenary interaction with realistic contact wire irregularities," Mechanism and Machine Theory, vol. 152, Article ID 103940, 2020.

[11] A. Bautista, J. Montesinos, and P. Pintado, "Dynamic interaction between pantograph and rigid overhead lines using a coupled FEM - multibody procedure," Mechanism and Machine Theory, vol. 97, pp. 100-111, 2016.

[12] Y. Song, Z. Liu, Z. Xu, and J. Zhang, "Developed moving mesh method for high-speed railway pantograph-catenary interaction based on nonlinear finite element procedure," International Journal of Reality Therapy, vol. 7, no. 3, pp. 173-190, 2019.

[13] Y. Song, A. Ronnquist, and P. Nåvik, "Assessment of the highfrequency response in railway pantograph-catenary interaction based on numerical simulation," IEEE Transactions on Vehicular Technology, vol. 69, no. 10, pp. 10596-10605, 2020.
[14] C. M. Pappalardo, M. D. Patel, B. Tinsley, and A. A. Shabana, "Contact force control in multibody pantograph/catenary systems," Proceedings of the Institution of Mechanical Engineers-Part K: Journal of Multi-Body Dynamics, vol. 230, no. 4, pp. 307-328, 2016.

[15] W. H. Zhang, G. M. Mei, X. J. Wu, and L. Q. Chen, "A study on dynamic behaviour of pantographs by using hybrid simulation method," Proceedings of the Institution of $\mathrm{Me}$ chanical Engineers-Part F: Journal of Rail and Rapid Transit, vol. 219, no. 3, pp. 189-199, 2005.

[16] L. Finner, G. Poetsch, B. Sarnes, and M. Kolbe, "Program for catenary-pantograph analysis, PrOSA statement of methods and validation according en 50318," Vehicle System Dynamics, vol. 53, no. 3, pp. 305-313, 2015.

[17] J.-W. Kim, H.-C. Chae, B.-S. Park, S.-Y. Lee, C.-S. Han, and J.-H. Jang, "State sensitivity analysis of the pantograph system for a high-speed rail vehicle considering span length and static uplift force," Journal of Sound and Vibration, vol. 303, no. 3-5, pp. 405-427, 2007.

[18] C. Vera, B. Suarez, J. Paulin, and P. Rodríguez, "Simulation model for the study of overhead rail current collector systems dynamics, focused on the design of a new conductor rail," Vehicle System Dynamics, vol. 44, no. 8, pp. 595-614, 2006.

[19] European Committee for Electrotechnical Standardization, EN. 50367. Railway Applications: Current Collection Systems-Technical Criteria for the Interaction between Pantograph and Overhead Line, European Standards (EN), Brussels, Belgium, 2016.

[20] Y. Song, H. Ouyang, Z. Liu, G. Mei, H. Wang, and X. Lu, "Active control of contact force for high-speed railway pantograph-catenary based on multi-body pantograph model," Mechanism and Machine Theory, vol. 115, pp. 35-59, 2017.

[21] P. Zdziebko, A. Martowicz, and T. Uhl, "An investigation on the active control strategy for a high-speed pantograph using co-simulations," Proceedings of the Institution of Mechanical Engineers - Part I: Journal of Systems \& Control Engineering, vol. 233, no. 4, pp. 370-383, 2019.

[22] J. Ambrósio, J. Pombo, and M. Pereira, "Optimization of high-speed railway pantographs for improving pantographcatenary contact," Theoretical and Applied Mechanics Letters, vol. 3, no. 1, Article ID 013006, 2013.

[23] E. Di Stefano, C. A. Avizzano, M. Bergamasco, P. Masini, M. Menci, and D. Russo, "Automatic inspection of railway carbon strips based on multi-modal visual information," in Proceeding of the 2017 IEEE International Conference on Advanced Intelligent Mechatronics (AIM), pp. 178-184, Munich, Germany, July 2017.

[24] M. Zhu, S. Y. Zhang, J. Z. Jiang et al., "Enhancing pantographcatenary dynamic performance using an inertance-integrated damping system," Vehicle System Dynamics, pp. 1-24, 2021.

[25] Y. Song, Z. Liu, F. Duan, X. Lu, and H. Wang, "Study on windinduced vibration behavior of railway catenary in spatial stochastic wind field based on nonlinear finite element procedure," Journal of Vibration and Acoustics, vol. 140, no. 1, Article ID 011010, 2018.

[26] Y. Song, Z. Liu, H. Wang, X. Lu, and J. Zhang, "Nonlinear analysis of wind-induced vibration of high-speed railway catenary and its influence on pantograph-catenary interaction," Vehicle System Dynamics, vol. 54, no. 6, pp. 723-747, 2016.

[27] Y. Song, M. Zhang, and H. Wang, “A response spectrum analysis of wind deflection in railway overhead contact lines 
using pseudo-excitation method," IEEE Transactions on Vehicular Technology, vol. 70, no. 2, pp. 1169-1178, 2021.

[28] M. Zhang, F. Xu, and O. Øiseth, "Aerodynamic damping models for vortex-induced vibration of a rectangular 4:1 cylinder: comparison of modeling schemes," Journal of Wind Engineering and Industrial Aerodynamics, vol. 205, Article ID 104321, 2020.

[29] M. T. Stickland, T. J. Scanlon, I. A. Craighead, and J. Fernandez, "An investigation into the mechanical damping characteristics of catenary contact wires and their," Proceedings of the Institution of Mechanical Engineers-Part F: Journal of Rail and Rapid Transit, vol. 217, pp. 63-72, 2001.

[30] T. J. Scanlon, A. B. Oldroyd, and A. B. Oldroyd, "An investigation into the attenuation of wind speed by the use of windbreaks in the vicinity of overhead wires," Proceedings of the Institution of Mechanical Engineers-Part F: Journal of Rail and Rapid Transit, vol. 214, no. 3, pp. 173-182, 2000.

[31] Y. Song, Z. Liu, H. Wang, J. Zhang, X. Lu, and F. Duan, "Analysis of the galloping behaviour of an electrified railway overhead contact line using the non-linear finite element method," Proceedings of the Institution of Mechanical Engineers-Part F: Journal of Rail and Rapid Transit, vol. 232, no. 10, pp. 2339-2352, 2018.

[32] W. M. Zhai and C. B. Cai, "Effect of locomotive vibrations on pantograph-catenary system dynamics," Vehicle System Dynamics, vol. 29, no. 1, pp. 47-58, 1998.

[33] Y. Song, Z. Wang, Z. Liu, and R. Wang, "A spatial coupling model to study dynamic performance of pantograph-catenary with vehicle-track excitation," Mechanical Systems and Signal Processing, vol. 151, Article ID 107336, 2021.

[34] Y. Yao, D. Zou, N. Zhou, G. Mei, J. Wang, and W. Zhang, "A study on the mechanism of vehicle body vibration affecting the dynamic interaction in the pantograph-catenary system," Vehicle System Dynamics, vol. 59, no. 9, pp. 1335-1354, 2020.

[35] Y. Yao, N. Zhou, G. Mei, and W. Zhang, "Dynamic analysis of pantograph-catenary system considering ice coating," Shock and Vibration, vol. 2020, pp. 2020-15, 2020.

[36] Y. Song, Z. Liu, and X. Lu, "Dynamic performance of highspeed railway overhead contact line interacting with pantograph considering local dropper defect," IEEE Transactions on Vehicular Technology, vol. 69, no. 6, pp. 5958-5967, 2020.

[37] F. Vesali, M. A. Rezvani, H. Molatefi, and M. Hecht, "Static form-finding of normal and defective catenaries based on the analytical exact solution of the tensile Euler-Bernoulli beam," Proceedings of the Institution of Mechanical Engineers-Part F: Journal of Rail and Rapid Transit, vol. 233, no. 7, pp. 691-700, 2019.

[38] Y. Song, Z. Liu, A. Rxnnquist, P. Navik, and Z. Liu, "Contact wire irregularity stochastics and effect on high-speed railway pantograph-catenary interactions," IEEE Transactions on Instrumentation and Measurement, vol. 69, p. 1, 2020.

[39] H. Wang, A. Núñez, Z. Liu, Y. Song, F. Duan, and R. Dollevoet, "Analysis of the evolvement of contact wire wear irregularity in railway catenary based on historical data," Vehicle System Dynamics, vol. 56, no. 8, pp. 1207-1232, 2018.

[40] O. Vo Van, J.-P. Massat, C. Laurent, and E. Balmes, "Introduction of variability into pantograph-catenary dynamic simulations," Vehicle System Dynamics, vol. 52, no. 10, pp. 1254-1269, 2014.

[41] H. Wang, Z. Liu, Y. Song, and X. Lu, "Ensemble EMD-based signal denoising using modified interval thresholding," IET Signal Processing, vol. 11, no. 4, pp. 452-461, 2017.

[42] Y. Song, A. Rønnquist, T. Jiang, and P. Nåvik, "Identification of short-wavelength contact wire irregularities in electrified railway pantograph-catenary system," Mechanism and Machine Theory, vol. 162, Article ID 104338, 2021.

[43] S. Pil Jung, Y. Guk Kim, J. Sung Paik, and T. Won Park, "Estimation of dynamic contact force between a pantograph and catenary using the finite element method," Journal of Computational and Nonlinear Dynamics, vol. 7, no. 4, Article ID 041006, 2012.

[44] D. Zou, N. Zhou, L. Rui Ping, G. M. Mei, and W. H. Zhang, "Experimental and simulation study of wave motion upon railway overhead wire systems," Proceedings of the Institution of Mechanical Engineers-Part F: Journal of Rail and Rapid Transit, vol. 231, no. 8, pp. 934-944, 2017.

[45] D. Zou, W. H. Zhang, R. P. Li, N. Zhou, and G. M. Mei, "Determining damping characteristics of railway-overheadwire system for finite-element analysis," Vehicle System Dynamics, vol. 54, no. 7, pp. 902-917, 2016.

[46] BSI, BS EN. 50317: Railway Applications: Current Collection Systems-Requirements for and Validation of Measurements of the Dynamic Interaction between Pantograph and Overhead Contact Line, British Standards Institution, London, UK, 2012.

[47] W. Zhang, N. Zhou, R. Li, G. Mei, and D. Song, "Pantograph and catenary system with double pantographs for high-speed trains at $350 \mathrm{~km} / \mathrm{h}$ or higher," Journal of Modern Transportation, vol. 19, no. 1, pp. 7-11, 2011.

[48] Z. Xu, Y. Song, and Z. Liu, "Effective measures to improve current collection quality for double pantographs and catenary based on wave propagation analysis," IEEE Transactions on Vehicular Technology, vol. 69, no. 6, pp. 6299-6309, 2020. 